\title{
La ruptura de matrimonios entre españoles y extranjeros con menores. Una estadística comparada
}

\author{
Juan Antonio Domínguez Álvarez \\ Instituto de Estudios Sociales Avanzados. Consejo Superior de Investigaciones Científicas \\ (IESA-CSIC) \\ jadominguez@iesa.csic.es
}

\section{Resumen}

En España, los matrimonios, los nacimientos y las disoluciones matrimoniales en el seno de hogares binacionales se han incrementado notablemente en los últimos años y, con ello, su relevancia social. El objetivo de este artículo es mostrar las peculiaridades de la ruptura en el caso de que un cónyuge sea español y el otro no, frente a lo que sucede cuando ambos cónyuges son españoles. Basándonos en una explotación del Boletín Estadístico de Nulidades, Separaciones y Divorcios del INE, podemos manifestar que existen diferencias entre ambos tipos de parejas en lo que se refiere a la duración del lapso entre la constitución y la disolución matrimonial, al tiempo que transcurre entre el comienzo y el fin del proceso de ruptura, al tipo de sentencia y a la custodia de los hijos.

Palabras clave: parejas binacionales; matrimonio mixto; pareja extranjera; etnicidad; separación matrimonial

Abstract. Rupture of marriages between Spaniards and foreigners with children: Comparative statistics

In Spain, marriages, births and the dissolution of marriages in binational households have increased notably in recent years, as well as the social impact of this phenomenon. The aim of this paper is to explore the specific characteristics of marital ruptures between Spanish and non-Spanish spouses and compare them to ruptures between Spanish-only couples. Using statistical data on annulments, separations and divorces published by the National Statistics Institute of Spain, the paper provides evidence of differences between both types of couples regarding 1) length of time between the marriage and the marital rupture, 2) length of the dissolution process, 3) type of sentence, and 4) child custody.

Keywords: binational couples; intermarriage; foreign couples; ethnicity; marital separation 


\section{Sumario}

1. Introducción 5. Análisis y resultados

2. Contextualización, hipótesis y objetivo

6. Conclusiones

3. Fuente de datos, marco y metodología

Referencias bibliográficas

4. Sin cobertura

\section{Introducción}

En el año 2012, estaban empadronados en España 5.736.258 ${ }^{1}$ extranjeros, que constituían un $12 \%$ de la población. Una masa crítica que se ha ido consolidando y que ha ido tejiendo interacciones sociales con la población autóctona.

Avalado por el desarrollo empírico sobre matrimonios y parejas mixtas (Steingress, 2012; Roca et al., 2010; Cortina et al., 2009; Alaminos, 2008; Santacreu y Francés, 2008), en su dimensión demográfica, el Instituto Nacional de Estadística (INE) ha acuñado el término mixtos para referirse a los matrimonios entre español y extranjero, con tal relevancia, que pasó a ser una categoría propia a partir de 2012. En dicho año, 23.675 (un 15\%) matrimonios celebrados con al menos un cónyuge español era mixto y 45.326 (un 12\%) nacidos con al menos un progenitor español era mixto.

Los interrogantes de los posibles efectos sobre la sociedad española desde el punto de vista de la existencia de familias mixtas constituyen el campo de investigación de autores como los mencionados en el párrafo anterior, incluso han dado pie a publicaciones monográficas como en OBETS: Revista de Ciencias Sociales (vol. 1) o en Papers: Revista de Sociología (vol. 97, núm. 1), así como diversos seminarios ${ }^{2}$ en el último lustro.

Aunque, hasta hoy, la orientación al hecho social de la interculturalidad y sus posibles efectos en nuestro país había puesto el foco en la formación de familias mixtas, la producción científica y la información demográfica sobre la ruptura de matrimonios mixtos es inexistente.

La ruptura de un matrimonio conlleva, para quien pasa por ese proceso y sus familiares, efectos jurídicos y económicos (Ruiz, 1999: 250), así como riesgos en la salud (Sbarra et al., 2011: 454) y psicosociales (Ruiz, 1999: 112), e incluso signos de vulnerabilidad en el ámbito del bienestar general (García y Solsona, 2011: 119). Estos efectos y factores de riesgo se traducen en costes para el Estado por lo que se refiere a la administración de justicia; a recursos sanitarios; a recursos sociales asociados a posibles efectos, como, por ejemplo,

1. Estadística del padrón continuo a 1 de enero de 2012 del Instituto Nacional de Estadística (INE).

2. «Interacciones culturales. Relaciones de género en los espacios de convivencia intercultural de las familias mixtas», IUDESP y Universidad de Alicante (2007); «Parejas binacionales en la sociedad avanzada», CENTRA y Universidad de Sevilla (2009), y «Seminario transnacional sobre familias interculturales», UNAF y Universidad de Málaga (2012). 
el fracaso escolar (Vallejo et al., 2004: 94), o a la relevante disminución en la recaudación tributaria por la desgravación de pensiones ${ }^{3}$.

Los efectos de la ruptura pueden magnificarse en una familia mixta con menores a cargo, por la posibilidad de que, tras aquélla, cambien el país de residencia habitual, lo cual dificulta la custodia compartida y/o un régimen de visitas saludable para los hijos, además, determina la desconexión, en muchos casos total, de una de las dos redes familiares de dicho menor, escenario propicio para su sustracción internacional por parte de alguno de los progenitores.

Este trabajo pone el foco, por primera vez, en la ruptura de un matrimonio mixto. Lo hace a través de un análisis descriptivo tras la exploración estadística comparada con la ruptura que tiene lugar cuando ambos cónyuges son españoles, de este modo, constituye un primer soporte cuantitativo del conocimiento de este fenómeno social en el ámbito de las ciencias sociales, jurídicas y económicas en materia de ruptura de matrimonios, como fenómeno de interés multidisciplinar y autónomo (Alberdi, 1981: 191), en un escenario lleno de tópicos (Jaime, 2000: 214).

\section{Contextualización, hipótesis y objetivo}

La investigación cuantitativa sobre ruptura de matrimonios mixtos españoles, aparte de la "precariedad estadística sobre el divorcio en España» (Simó y Solsona, 2010: 610) y el coste ${ }^{4}$ de los datos, es nula, pues éstos no recogen la variable nacionalidad. Esto desanima y explica en parte el poco desarrollo empírico (Rondón, 2012: 147) sobre la gestión de conflictos y rupturas familiares en un contexto de formación e interacción social de familias mixtas. De hecho, podemos afirmar, sobre el estado de la cuestión, que existe un vacío temático alarmante en la investigación sobre las rupturas de hogares mixtos con hijos a cargo y sus trayectorias familiares posteriores. Se puede considerar alarmante por dos hechos constatados:

1. El fuerte incremento de $\operatorname{casos}^{5}$ de solicitud de visita o de sustracción transfronteriza de niños por parte de uno de sus progenitores con origen o destino en España: 78 en 1999, 153 en 2003, 204 en 2008 y 214 en 2012. Los datos anteriores son sólo referentes a países que tienen suscrito un convenio ${ }^{6}$, es decir, limitado al $44 \%$ de los que mantienen relaciones diplomáticas que tiene identificado el INE. Además, su correlación con las sentencias de divorcio no consensuado o separación contenciosa es muy plausible.

3. En el año 2010, se abonaron al menos 464,7 millones de euros en pensiones a los cónyuges y 1.288 millones de euros en pensiones alimenticias a los hijos. Fuente: AEAT-Estadística IRPF, casillas 585 y 688 .

4. Sometidos a unas tarifas publicadas en el BOE de 1 de marzo de 2010.

5. Casos a partir de las estadísticas que elabora Hague Conference on Private International Law $(\mathrm{HccH})$.

6. Convenio de la Haya, de 25 de octubre de 1980, sobre la sustracción internacional de menores por parte de sus progenitores. 
2. En ausencia de un marco legal internacional o regional aplicable, la única solución posible es la mediación y demás métodos alternativos de resolución de conflictos (Vidal, 2010: 125) y, para éstos, no es viable avanzar sin investigación académica.

En el año 2007, la estadística de disoluciones matrimoniales empieza a recoger la variable nacionalidad de los cónyuges, de manera que, al haberse cubierto un lustro, este artículo resuelve una exploración inédita de datos y plantea como hipótesis que el hecho de tener menores binacionales a cargo provoca que el proceso de ruptura matrimonial entre un cónyuge español y otro extranjero sea distinto al proceso que se sigue cuando ambos son españoles.

El objetivo es cuantificar y medir las características de las rupturas matrimoniales entre un cónyuge español y otro extranjero con hijos menores, en comparación con la ruptura matrimonial que se da cuando ambos cónyuges son españoles con hijos menores, $y$, en este sentido, para una misma generación de individuos, poder responder si hay diferencias o no sobre la duración del matrimonio, el tiempo que transcurre entre el comienzo y el fin del proceso de separación, el tipo de sentencia y la custodia de los hijos.

\section{Fuente de datos, marco y metodología}

La fuente principal de donde provienen los datos para este trabajo es el Boletín Estadístico de Nulidades, Separaciones y Divorcios del Instituto Nacional de Estadística (INE), producido por el Consejo General del Poder Judicial (CGPJ), en adelante INE-NSD, para las sentencias judiciales del periodo 2007-2011.

El Boletín INE-NSD, de periodicidad anual, desde el año 2007, incluye las variables: provincia, comunidad autónoma, fecha de la demanda de divorcio, fecha de la sentencia, fecha del matrimonio, fecha de nacimiento de los cónyuges, estado civil antes del matrimonio, nacionalidad de los cónyuges, sexo de los cónyuges, número de hijos menores, número de hijos mayores dependientes, quién demanda, tipo de sentencia, pensión compensatoria, pensión de alimentos, custodia de hijos y separación previa. Y, a partir de ellas, se han construido las variables: días entre demanda y sentencia, disolución hispano-extranjera y grupo geopolítico según nacionalidad de los cónyuges. Además de una variable de peso, que resuelve los problemas de cobertura ${ }^{7}$.

Dos fuentes complementarias usadas son los microdatos de matrimonios de los años 1989 a 2011 y los microdatos de nacimientos de los años 2007 a 2011, ambos producidos por el INE.

Jurídicamente, los procesos de ruptura matrimonial que recoge el Boletín INE-NSD se rigen por la Ley 30/1981 y su reforma (Ley 15/2005). Antes de junio de 2005, el proceso era bietápico, se requería una sentencia de separación previa y, posteriormente, se podía demandar el divorcio. En la actualidad, el

7. <http://www.ine.es/metodologia/t18/t1830420p01.htm> [Consulta: 1 febrero 2013]. 
Tabla 1. Sentencias de ruptura de matrimonios con al menos un cónyuge español y con al menos un hijo menor en el periodo que va de 2007 a 2011

\begin{tabular}{lccc}
\hline \multicolumn{1}{c}{ Tipo de sentencia } & $\begin{array}{c}\text { Hombre } \\
\text { español y mujer español y mujer } \\
\text { española con } \\
\text { menor(es) }\end{array}$ & $\begin{array}{c}\text { Hombre } \\
\text { extranjera con } \\
\text { menor(es) }\end{array}$ & $\begin{array}{c}\text { Hombre } \\
\text { mujer españoro y } \\
\text { muja } \\
\text { con menor(es) }\end{array}$ \\
\hline Separación de mutuo acuerdo & 15.118 & 289 & 298 \\
Separación contenciosa & 6.569 & 217 & 228 \\
Divorcio consensuado sin separación previa & 144.297 & 4.032 & 4.067 \\
Divorcio no consensuado sin separación previa & 66.678 & 2.779 & 2.794 \\
\hline
\end{tabular}

Fuente: elaboración propia a partir de INE-NSD 2007-2011.

Boletín del INE-NSD contabiliza tres hechos distintos (nulidades, separaciones y divorcios), y el divorcio pueden estar o no precedido por separación.

La nulidad es el ejemplo más atípico y los divorcios precedidos por separación pueden causar duplicidad de datos para el periodo de análisis. Por ello, se delimita el estudio a las separaciones y a los divorcios sin separación previa, usando el término «ruptura» cuando se traten ambos hechos de forma agregada.

Centrados en rupturas de matrimonios heterosexuales con hijos menores, no sólo se reduce el ruido producido por la heterogeneidad de motivos de constitución y disolución de matrimonios, sino que también se acotan los rangos de edad, con lo cual se homogeneizan los grupos de madres españolas y madres extranjeras por el hecho biológico de tener hijos menores.

Por lo descrito anteriormente, los casos que configuran el marco de análisis (tabla 1) son las rupturas de matrimonios heterosexuales con al menos un menor de edad a cargo y al menos uno de los dos cónyuges con nacionalidad española, quedando excluidas las nulidades y los divorcios con separación previa. Depurando el fichero, ya tenemos una cuantificación de 247.366 rupturas (14.704 de ellas mixtas) que afectan al menos ${ }^{8}$ a 374.769 menores (20.897 de ellos mixtos) en un lapso de tan sólo 5 años, si bien, en el primer apartado de análisis (5.1), se usará la totalidad de los registros del Boletín INE-NSD, donde al menos un cónyuge es español, que evidencia mayor ruptura en matrimonios mixtos, tengan o no hijos.

Una grave deficiencia del Boletín INE-NSD es que no recoge si la nacionalidad es de origen o no y, por tanto, en la tabla 1, algún caso podría no estar en la celda adecuada o incluso salirse del marco. Estos ejemplos ocultos se dan fundamentalmente en el grupo de cónyuges en que ambos son españoles en el momento de la ruptura, pero en que la pareja es mixta en el momento de la unión, y, hoy por hoy, tiene un peso más que residual en el total del grupo que contempla la situación en la que ambos son españoles, por lo que no pone en riesgo los análisis actuales. No obstante, esta grave deficiencia sí pone en riesgo los futuros y necesarios análisis longitudinales.

8. La variable número de hijos menores agrupa todos los valores superiores a 9. El número de casos de rupturas puede fluctuar de 2 a 3 unidades, dependiendo del cruce, debido a la ponderación (ver nota 7). 
Para contrastar diferencias o no entre los tipos de matrimonios, se analizará la T de Student para muestras independientes y, además, la prueba no paramétrica U de Mann-Whitney en variables de escala (duración de matrimonio y proceso de ruptura); se usarán también el coeficiente phi o el coeficiente de contingencia, según la dimensión de la tabla de contingencia para variables nominales (tipos de demanda, de sentencia y de resoluciones). Estos contrastes han sido abordados para grupos generacionales conexos, con el factor de tener un menor a cargo en el periodo acotado de 2007 a 2011. Cohesionados entre 25 y 49 años, encontramos que el $87 \%$ de los esposos y el $94,4 \%$ de las esposas tienen 49 años o menos, y sólo el $0,4 \%$ de los esposos y el 1,2\% de las esposas tienen menos de 25 años.

\section{Sin cobertura}

Antes de pasar al apartado de análisis de ruptura de matrimonios, es necesario poner de manifiesto que la investigación sobre la ruptura y la postruptura de parejas, y más cuando ésta pivota sobre menores, carece de fuentes estadísticas de primer nivel sobre sentencias y regulaciones de rupturas no matrimoniales (uniones consensuales), "de las cuales apenas conocemos su importancia numérica» (Simó y Solsona, 2010), más allá de conteos anuales muy agregados, como, por ejemplo, el expuesto en la tabla 2, por el que se asume la cifra en valor absoluto para 2011 de 31.202 rupturas con hijos (si, como mínimo, un miembro de la pareja fuera español, representarían el 34\% de las rupturas total de parejas, con al menos un menor español a cargo para el 2011), y de la que podemos saber que el porcentaje de rupturas no consensuadas que contemplan hijos no matrimoniales es del 69\%, frente al 31\% de rupturas consensuadas, para el periodo 2007-2011.

$\mathrm{Si}$, como se verá más adelante en el apartado 5.3.3, que, para el periodo 2007-2011, los divorcios no consensuados de matrimonios con menores eran del 29\% en matrimonios en los que ambos eran españoles, y del 38\% para matrimonios mixtos, este peso invertido de las rupturas no consensuadas para uniones no matrimoniales puede dejar abrumados a los investigadores, huérfanos de una fuente estadística oficial de ruptura dimensionada a la totalidad de las que se han producido (matrimonial y de unión consensual), y, más

Tabla 2. Número de sentencias producidas en los tribunales superiores de justicia que contemplan hijos no matrimoniales

\begin{tabular}{ccc}
\hline Año & $\begin{array}{c}\text { Guardia, custodia y alimentos } \\
\text { de hijos no matrimoniales } \\
\text { consensuados por TSJ }\end{array}$ & $\begin{array}{c}\text { Guardia, custodia y alimentos } \\
\text { de hijos no matrimoniales no } \\
\text { consensuados por TSJ }\end{array}$ \\
\hline 2007 & 5.534 & 12.677 \\
2008 & 6.104 & 14.493 \\
2009 & 6.992 & 16.483 \\
2010 & 9.017 & 19.051 \\
2011 & 10.214 & 20.988 \\
2012 & 12.018 & 23.283 \\
\hline
\end{tabular}

Fuente: Consejo General del Poder Judicial (CGPJ). Estadística judicial. 
Gráfico 1. Evolución de porcentajes sobre niños nacidos de progenitores no casados en el año de su nacimiento, para el periodo de 1996 a 2011

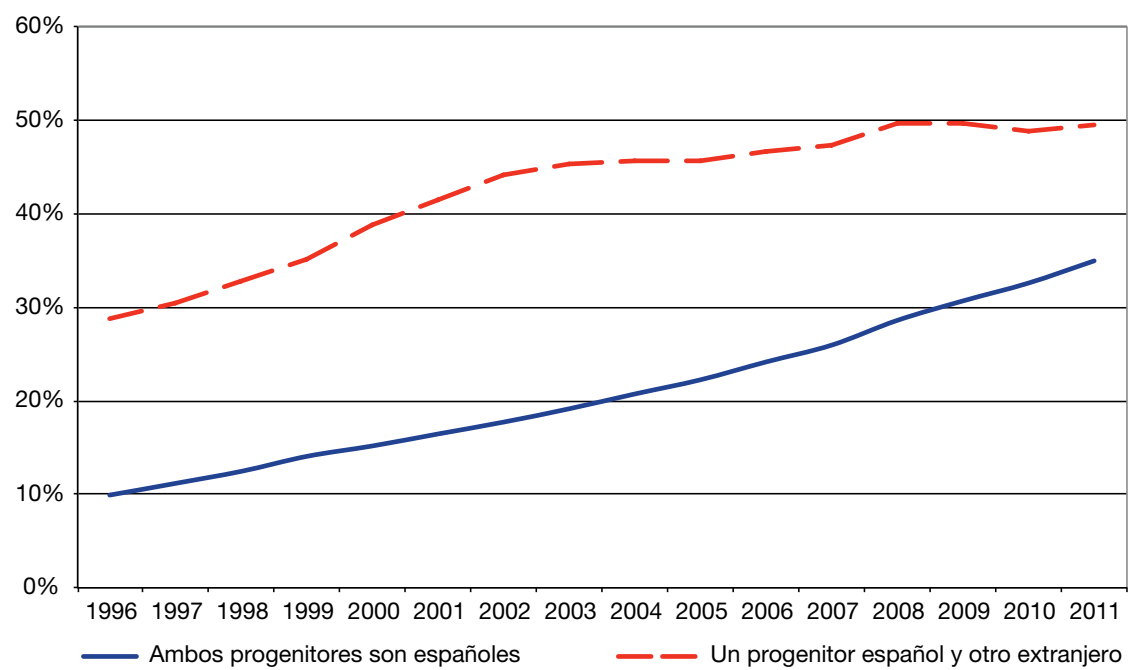

Fuente: INE microdatos de nacimientos 1996-2011. Elaboración propia.

específicamente, a los investigadores de uniones mixtas, teniendo en cuenta el elevado porcentaje de los hijos habidos en uniones mixtas entre progenitores no casados en el momento de nacer sus criaturas, como refleja el gráfico 1 . Aunque, con posterioridad al nacimiento, contraigan matrimonio, no dejaría de ser una cifra significativa y, en consecuencia, podría darse una cantidad no menos importante de rupturas en el ámbito de parejas no matrimoniales.

La carencia de datos directos conlleva a abordar la investigación en su completitud (matrimonial y de unión consensual) por medio de encuestas como la de fecundidad y familia (1995) o la sociodemográfica (1991) u otros métodos ad hoc, que o bien no dan respuestas en todos los niveles de desagregación, o bien tienen un coste inasumible.

En este trabajo de análisis inédito de rupturas mixtas, se debe tener la prudencia de reflejar que se está analizando a un subconjunto de rupturas (las matrimoniales con al menos un cónyuge español y al menos un menor) que representan el $72 \%$ de ellas, con al menos un español en la pareja y al menos un menor en el periodo 2007-2011.

\section{Análisis y resultados}

\subsection{Diferencias sociodemográficas}

Se están analizando grupos generacionales conexos, en los que, en el 84,5\% de los casos en que ambos cónyuges son españoles, tienen entre 25 y 49 años, 
tanto el esposo como la esposa, y para los casos mixtos el porcentaje es del $79,3 \%$. Esta diferencia es consecuencia de los casos mixtos de esposo español y esposa extranjera, donde el esposo destaca por tener más años y presentar mayor distancia de edad con la esposa extranjera. Para los casos de esposa española y esposo extranjero, es equiparable a los ejemplos en que ambos son españoles.

La otra diferencia destacable es la trayectoria prenupcial, de la que también destacan los casos mixtos de esposo español y esposa extranjera, donde el porcentaje de esposos previamente divorciados es significativamente mayor.

Por tanto, se tomará en cuenta si las variables diferencia de edad y estado civil prenupcial influyen en posibles aspectos de la duración, la demanda, la sentencia o la regulación postruptura.

\subsection{Cuantificación de rupturas matrimoniales mixtas y en la que ambos son españoles}

En una primera observación de la diferencia entre rupturas de matrimonios mixtos frente a matrimonios donde ambos son españoles, usamos la totalidad de disoluciones (separaciones, divorcios y nulidades) donde al menos exista un cónyuge español, en un análisis longitudinal representado por el gráfico 2, donde los puntos de la gráfica se calculan a partir de:

Numerador: suma de disoluciones del periodo 2007-2011 cuyo matrimonio se celebró en el año X.

Denominador: matrimonios celebrados dicho año X.

X toma los valores de 1989 a 2011 (el primer año de matrimonio corresponde a 2011).

El análisis individual de cada curva no es preciso, porque carece de los datos de disolución del periodo 1989-2006 y, aún teniéndolos, existirían fenómenos perturbadores (migraciones, mortalidad, duplicidad por separación previa, matrimonio celebrado fuera de España y cambio de nacionalidad). No obstante, tiene interés comparar ambas curvas, porque, en igualdad de perturbaciones, el porcentaje de disoluciones mixtas empezaría a ser muy superior a partir del quinto año de matrimonio, incluso podría llegar a duplicarlo.

El periodo sombreado del gráfico 2, de uno a cinco años de vida del matrimonio, tiene un efecto reducido a las carencias mencionadas, $y$, desagregando las disoluciones con hijos y sin hijos, se amplía en el gráfico 3, con la siguiente representación:

a) Para los dos grupos con hijos

Numerador: [disoluciones entre 2007 y 2011, cuyo matrimonio se celebró en el año X]. Denominador: [nacimientos de primogénitos entre 2007 y 2011 de progenitores casados en el año X]. 
Gráfico 2. Porcentaje de disoluciones de matrimonios en el periodo 2007-2011 por año de celebración del matrimonio entre 1989 y 2011

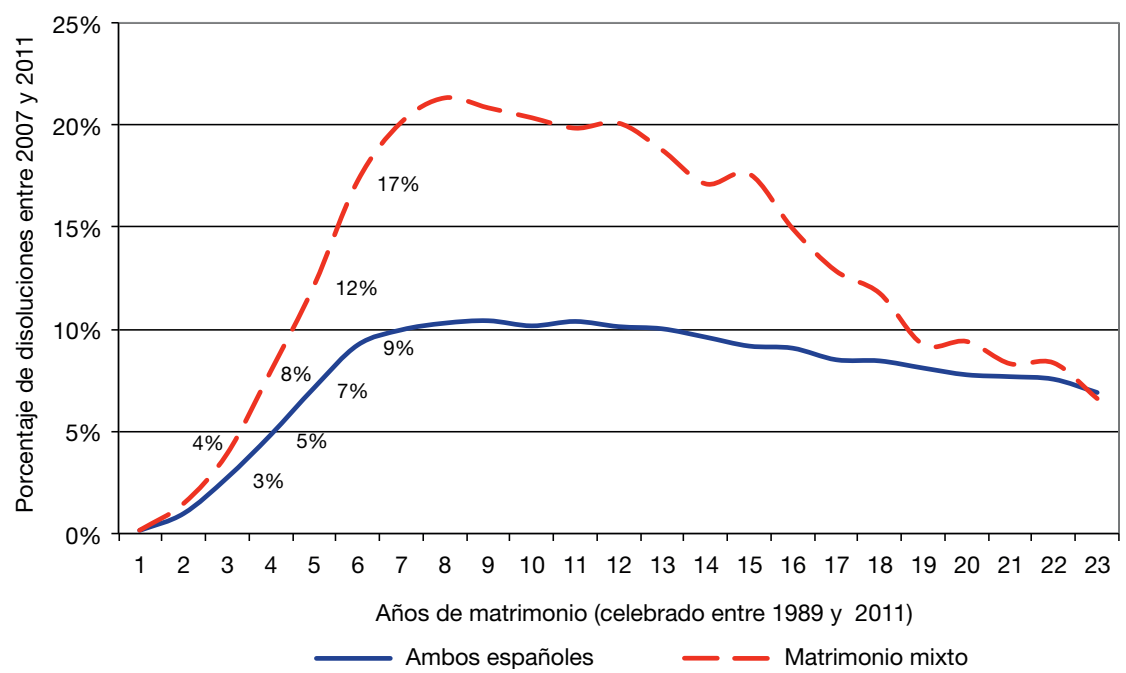

Fuente: elaboración propia a partir de INE-NSD 2007-2011 e INE, microdatos de matrimonios celebrados entre 1989 y 2011.

\section{b) Para los dos grupos sin hijos}

Numerador: [disoluciones entre 2007 y 2011, cuyo matrimonio se celebró en el año X]. Denominador: [(matrimonios celebrados ese año X) - (nacimientos de primogénitos entre 2007 y 2011 de progenitores casados en el año X)]

La observación del gráfico 3 sigue situando a los matrimonios mixtos con porcentajes de ruptura sustancialmente mayores. Y para el marco referente a los casos con hijos, en el quinto año de unión se ha separado o divorciado un $7,6 \%$ de matrimonios mixtos frente al 4,3\% de matrimonios donde ambos son españoles.

Centrados en el marco de análisis de 247.366 sentencias (casos de separaciones y divorcios sin separación previa con al menos un cónyuge español y como mínimo un menor a cargo) entre 2007 y 2011, en valores absolutos (tabla 3), de 2007 a 2009, ha cambiado la tendencia regular ascendente de rupturas de 1981 a 2007 (Solsona, 2011: 79). Aunque sólo para cónyuges en los que ambos son españoles, debe contemplarse el hecho de que la crisis económica actual propicia su decisión de retrasar la separación o el divorcio, por el quebranto o el perjuicio económico que deben asumir. Sin embargo, en 2010 sube, esto da consistencia a la idea de que la decisión de disolver el matrimonio no es abandonada, sino que tan sólo se pospone a la espera de una mejoría en la situación económica, que no se da cuando, en 2010 y 2011, la crisis, en vez de amainar, arrecia. Ocurre que el aumento no es de la intensidad de 2005 a 
Gráfico 3. Porcentaje de disoluciones de matrimonios en el periodo 2007 y 2011 por año de celebración del matrimonio entre 2007 y 2011

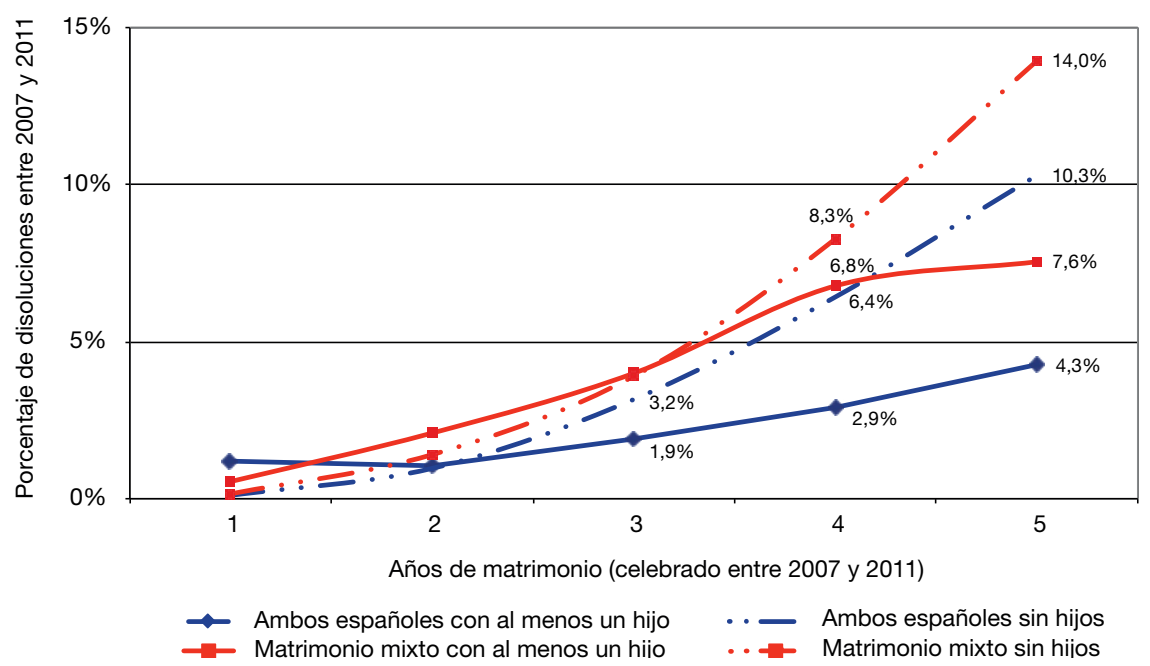

Fuente: elaboración propia a partir de INE-NSD 2007-2011, INE-microdatos de matrimonios 07-11, INEmicrodatos de nacimientos 07-11.

2007, tras el cambio normativo (Solsona, 2011: 79), por existir un periodo de reflexión mayor para los cónyuges, que en 2007-2009 habían prorrogado la decisión, aunque habría que considerar también el factor de la carga y los recursos judiciales, que modulan el flujo de sentencias respecto a las demandas.

Para los matrimonios mixtos del marco, se observa un comportamiento distinto. De hecho, mantienen la tendencia histórica (al alza con el cambio normativo de 2005), a su vez, que va ganando peso relativo del total de rupturas del marco (tabla 3), aunque esto último se explica por el incremento también del peso relativo en las uniones matrimoniales, que, en la última década, ha crecido del $7 \%$ de 2002 al $15 \%$ de 2012 .

Tabla 3. Número de sentencias por año, con al menos un cónyuge español y al menos un menor a cargo

\begin{tabular}{cccc}
\hline Año & $\begin{array}{c}\text { Sentencias } \\
\text { ambos españoles }\end{array}$ & $\begin{array}{c}\text { Sentencias } \\
\text { mixtas }\end{array}$ & $\begin{array}{c}\text { Peso de } \\
\text { rupturas mixtas }\end{array}$ \\
\hline 2007 & 48.835 & 2.388 & $4,7 \%$ \\
2008 & 46.705 & 2.838 & $5,7 \%$ \\
2009 & 43.406 & 2.861 & $6,2 \%$ \\
2010 & 46.446 & 3.201 & $6,4 \%$ \\
2011 & 47.270 & 3.416 & $6,7 \%$ \\
\hline
\end{tabular}

Fuente: elaboración propia a partir de INE-NSD 2007-2011. 


\subsection{Duración de los matrimonios mixtos y en los que ambos miembros son españoles}

Para el conjunto de las 247.366 rupturas objeto de análisis, desagregados en dos grupos (ambos españoles $N=232.662$, y mixtos $N=14.704$ ), tomando la duración como el valor entre la fecha del matrimonio y la fecha de presentación de la demanda (inicio del proceso de ruptura), evitando así la interferencia del tiempo entre demanda y sentencia, tenemos que la duración media entre matrimonio y demanda en el caso en que ambos cónyuges son españoles ha sido de 13,3 años, y para los mixtos, de 9,5 años. La prueba $T$ rechaza la hipótesis de igualdad de medias $(\alpha=0,01)$ y la prueba no paramétrica $U$ de Mann-Whitney rechaza la hipótesis de igualdad de distribución $(\alpha=0,01)$. La duración ha sido de media un $28 \%$ más corta en los matrimonios mixtos.

Para el contraste sobre diferencia de edad, se cuenta con 244.744 casos, desagregados en dos grupos (diferencia de 0 a 8 años $N=223.397$ y diferencia de 9 o más años $N=21.347$ ). Tenemos que la duración media en matrimonios con menor diferencia de edad es de 13,3 años, y con mayor diferencia de edad (superior a 9) es de 11 años. La prueba $T$ rechaza la hipótesis de igualdad de medias $(\alpha=0,01)$, y la prueba no paramétrica $U$ de Mann-Whitney rechaza la hipótesis de igualdad de distribución $(\alpha=0,01)$. La duración ha sido de media un 17\% más corta en los matrimonios en que existe mayor diferencia de edad entre los cónyuges. Si consideramos sólo el conjunto de 150.546 casos, donde la diferencia de edad está entre 0 y 3 años, desagregados en dos grupos (ambos españoles $N=$ 144.145, y mixtos $N=6.400$ ), tenemos que la duración media entre la celebración del matrimonio y la demanda de nulidad en el caso en que ambos cónyuges son españoles ha sido de 13,5 años, y para los mixtos, de 10,3 años. La prueba T rechaza la hipótesis de igualdad de medias $(\alpha=0,01)$, y la prueba no paramétrica $\mathrm{U}$ de Mann-Whitney rechaza la hipótesis de igualdad de distribución $(\alpha=0,01)$. La duración ha sido de media un $10 \%$ más corta en los matrimonios mixtos.

Podemos afirmar que la distancia de edad entre cónyuges explica sólo en parte la menor duración de media de los matrimonios mixtos frente a los matrimonios en los que ambos son españoles, puesto que, a mismas edades, siguen persistiendo diferencias.

Para el contraste de estado civil prenupcial, se cuenta con 233.774 casos, desagregados en dos grupos (divorciado y soltera $N=8.356$, y soltero y soltera $N=225.418$ ). Tenemos que la duración media del matrimonio entre divorciado y soltera es de 9,8 años, y en los casos de soltero y soltera, de 13,3 años. La prueba T rechaza la hipótesis de igualdad de medias $(\alpha=0,01)$, y la prueba no paramétrica U de Mann-Whitney rechaza la hipótesis de igualdad de distribución $(\alpha=0,01)$. La duración ha sido de media un $27 \%$ más corta en los matrimonios formados por divorciado y soltera. Si consideramos el conjunto de 225.418 casos donde ambos son solteros, desagregados en dos grupos (ambos españoles $N=213.763$, y mixtos $N=11.655$ ), tenemos que la duración media entre matrimonio y demanda para ambos cónyuges españoles ha sido de 13,5 años, y para mixtos, de 9,9 años. La prueba T rechaza la 
hipótesis de igualdad de medias $(\alpha=0,01)$ y la prueba no paramétrica $U$ de Mann-Whitney rechaza la hipótesis de igualdad de distribución $(\alpha=0,01)$. La duración ha sido de media un $27 \%$ más corta en los matrimonios mixtos.

Podemos afirmar que el estado civil prenupcial explica sólo en parte la menor duración de media de los matrimonios mixtos frente a los matrimonios en los que ambos miembros son españoles, puesto que, a igualdad prenupcial (ambos solteros en los dos grupos), siguen persistiendo diferencias.

A la vista de los resultados, se podría refutar que "Cuanto más recientes son las generaciones o promociones de unión, más grande es la probabilidad de ruptura a cualquier duración de la unión» (Houle et al., 1999: 20). Sin dejar de ser cierto para el contraste entre promociones en los que ambos son españoles, surge con fuerza el factor mixto como efecto perturbador en el comportamiento de duración de un matrimonio. Con el inquietante rango del 10\% al 28\% (dependiendo de factores sociodemográficos), es más corta de media la duración de éstos en matrimonios con hijos de las mismas generaciones.

\subsection{El camino de los procesos judiciales en los matrimonios mixtos $y$ en los que ambos miembros son españoles}

\subsubsection{La demanda}

La primera acción una vez tomada la decisión de emprender la ruptura matrimonial es interponer una demanda de separación o divorcio, que puede ser

Gráfico 4. Función de supervivencia de las demandas de separación o divorcio sin separación previa de al menos un cónyuge español con al menos un menor, según quien sea la persona demandante (2007-2011)

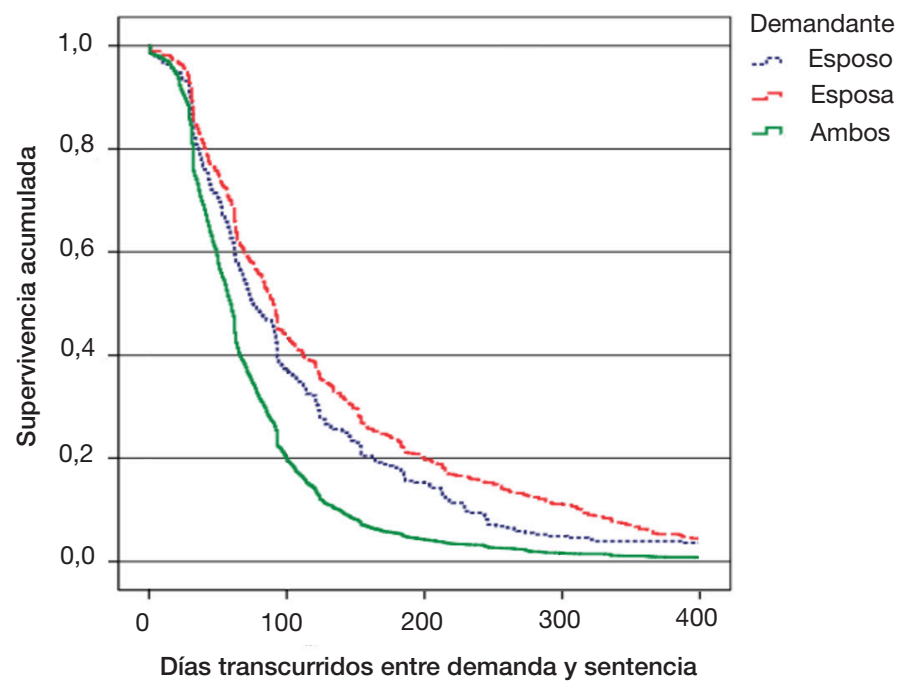

Fuente: elaboración propia a partir de INE-NSD 2007-2011. 
conjunta o no. Podemos interpretar que, cuando la demanda es conjunta, el nivel de entendimiento para afrontar la ruptura es mayor, lo cual da pie a un proceso con menor tensión y es más probable llegar a una sentencia de divorcio consensuado o de separación de mutuo acuerdo (Solsona y Simó, 2007).

La demanda conjunta en matrimonios con hijos menores, donde ambos eran españoles, fue presentada en el $49 \%$ de los 232.662 casos del periodo 2007-2011. Esta cifra se reduce significativamente para los 14.704 casos de matrimonios mixtos al $37 \%$.

También la demanda conjunta reduce sustancialmente la duración del proceso, como se aprecia en el gráfico 4. Cuando la demanda es conjunta, transcurridos 60 días, queda un 38\% de casos por resolver. Si la ha presentado la esposa, queda el $80 \%$ de los casos, y si la ha presentado el esposo, el $75 \%$ de los casos, en un proceso muchísimo más lento.

En las 127.603 demandas individuales, se ratifica un hecho que se constató para el periodo 1996-2002, el "fuerte desequilibrio entre sexos» (Solsona y Simó, 2007: 272). Sigue siendo mucho más frecuente que la demandante sea la esposa, y esto se interpretó como «un reclamo de establecer unas condiciones justas en la postruptura» (Solsona y Simó, 2007: 272), aunque llama la atención otro desequilibrio dentro del conjunto de esposas, entre las cuales destaca la española casada con un extranjero $(N=4.602)$, donde, de las demandas individuales, el $78 \%$ las presenta ella. Para demandas individuales de matrimonios en que ambos son españoles $(N=118.401)$, el $68 \%$ las presenta la esposa, y para demandas individuales de parejas mixtas de mujer extranjera y hombre español $(N=4.600)$, el $61 \%$ las presenta también la esposa.

Para una tabla de contingencia entre demandante y diferencia de edad (de 0 a 8 , y de 9 y más), en que el valor del coeficiente de contingencia es 0,033 , se descarta que exista relación. Para una tabla de contingencia entre demandante y estado civil prenupcial (divorciado con soltera y soltero con soltera), en que el valor del coeficiente de contingencia es 0,021 , se descarta que exista relación. Las diferencias sociodemográficas apreciables entre rupturas mixtas y rupturas en los que ambos miembros de la pareja son españoles, no explican las diferencias en la interposición de la demanda, y existen menos demandas conjuntas en las rupturas mixtas.

A partir del tipo de demanda, los datos nos llevan a asumir que los matrimonios mixtos, en general, y de esposa española, en particular, se enfrentan a mayores sentencias de divorcios no consensuados y de separaciones contenciosas, así como a procesos de ruptura mucho más lentos.

\subsubsection{La duración del proceso judicial}

La duración del proceso judicial refleja el tiempo que transcurre entre la fecha de demanda y la fecha en la que se produce la sentencia. Sabemos que «el nivel de entendimiento entre los cónyuges que disuelven su unión reduce enormemente la duración del proceso» (Solsona y Simó, 2007: 271), y es razonable pensar que la dilatación del proceso produce mayor tensión para los cónyuges, que puede quebrar dicho nivel de entendimiento. 
La reforma del proceso (Ley 15/2005), además de eliminar el requisito de separación como paso previo a la obtención del divorcio, trata de acelerarlo, de forma que, en caso de mutuo acuerdo por parte de los cónyuges, el divorcio pueda hacerse efectivo en dos o tres meses (Simó y Solsona, 2010), y así ha sucedido en el 73\% (acumulado 0-3 meses) de los divorcios consensuados sin separación previa y en el $76 \%$ de las separaciones de mutuo acuerdo, entre españoles con hijos en el periodo 2007-2011. Para las rupturas mixtas entre hombre español y mujer extranjera, la duración ha sido inferior a cuatro meses en el 69\% de los casos de divorcio y en el 63\% de los casos de separaciones. Para las rupturas mixtas entre mujer española y hombre extranjero, la duración ha sido inferior a cuatro meses en el 68\% de los casos de divorcio y en el $75 \%$ de los casos de separaciones, por lo que se pone de manifiesto lo siguiente:

a) Se acorta la distancia entre la duración de las separaciones y la duración de los divorcios sin separación previa entre españoles. En el periodo 19962002, había una distancia de 7 puntos entre el porcentaje de sentencias resueltas de separaciones y divorcios con separación previa en los 2 primeros meses, a favor de las separaciones (Simó y Solsona, 2010).

b) La reforma del proceso (Ley 15/2005) no acelera los procesos mixtos tanto como los procesos donde ambos son españoles, cuando éstos son consensuados o de mutuo acuerdo.

c) Dura más el proceso de separación de matrimonios mixtos de hombre español, que el de matrimonios mixtos de mujer española. De este modo, éste último se equipara a los matrimonios en los que ambos miembros son

Gráfico 5. Duración del proceso de separaciones de mutuo acuerdo con hijos menores (2007-2011)

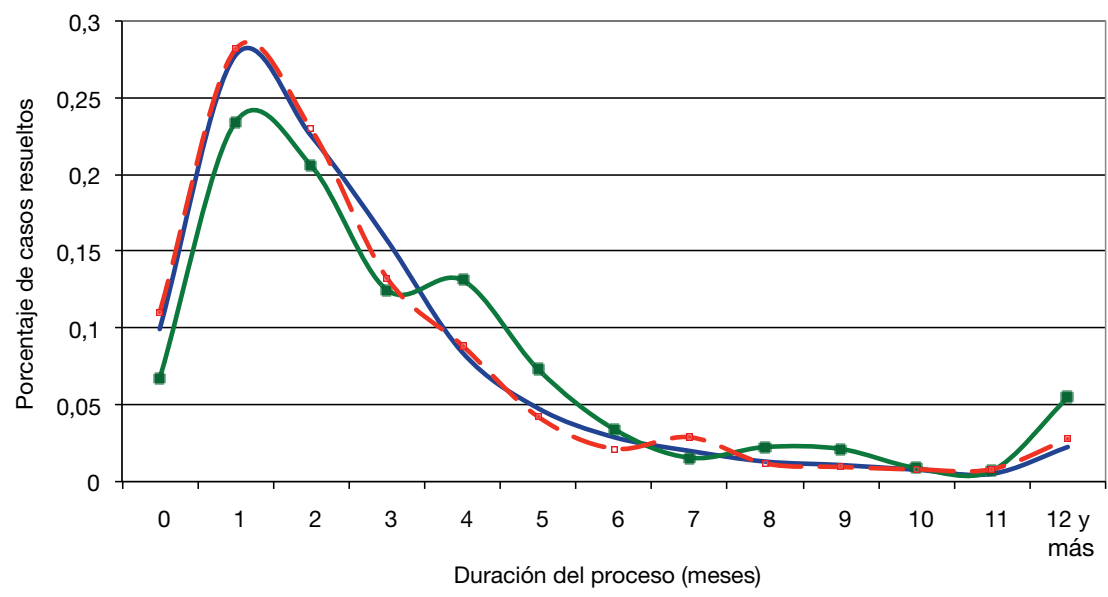

- Ambos españoles $=$ Hombre español y mujer extranjera - Mujer española y hombre extranjero

Fuente: elaboración propia a partir de INE-NSD 2007-2011. 
españoles (gráfico 5). En los primeros 3 meses, la distancia del porcentaje acumulado es de 12 puntos.

Para el conjunto de las 247.366 rupturas objeto de análisis, tenemos que la duración media entre demanda y sentencia para ambos cónyuges españoles ha sido de 4,86 meses $(N=232.662)$, y para mixtos, de 6,23 meses $(N=14.704)$. La prueba $T$ rechaza la hipótesis de igualdad de medias $(\alpha=0,01)$, y la prueba no paramétrica U de Mann-Whitney rechaza la hipótesis de igualdad de distribución $(\alpha=0,01)$. La duración del proceso ha sido de media un $28 \%$ más larga en los matrimonios mixtos.

Para el conjunto de las 14.704 rupturas mixtas, tenemos que la duración media entre demanda y sentencia de hombre español y mujer extranjera ha sido de 6,18 meses $(N=7.316)$ y de mujer española y hombre extranjero, de 6,28 meses $(N=7.387)$. La prueba $T$ acepta la hipótesis de igualdad de medias $(\alpha=0,01)$, y la prueba no paramétrica U de Mann-Whitney confirma la hipótesis de igualdad de distribución $(\alpha=0,01)$. Tienen la misma distribución, con una duración un $2 \%$ más larga en matrimonios mixtos de esposo español.

Para el conjunto de las 586 separaciones mixtas de mutuo acuerdo, tenemos que la duración media entre demanda y sentencia de hombre español y mujer extranjera ha sido de 3,6 meses $(N=289)$ y de mujer española y hombre extranjero, de 2,86 meses $(N=298)$. La prueba T rechaza la hipótesis de igualdad de medias con un valor $p=0,044(\alpha=0,01)$, y la prueba no paramétrica $U$ de Mann-Whitney rechaza la hipótesis de igualdad de distribución $(\alpha=0,01)$. La duración de la separación mixta de mutuo acuerdo ha sido de media un $26 \%$ más corta en los matrimonios mixtos de mujer española, lo cual confirma lo observado en la gráfica 5 para este caso muy concreto de rupturas.

Si consideramos sólo el conjunto de 150.546 casos, donde la diferencia de edad está entre 0 y 3 años, desagregados en dos grupos (ambos españoles $N=144.145$, y mixtos $N=6.400$ ), tenemos que la duración media entre demanda y sentencia para ambos cónyuges españoles ha sido de 4,75 meses, y para mixtos, de 6,00 meses. La prueba T rechaza la hipótesis de igualdad de medias $(a=0,01)$, y la prueba no paramétrica $U$ de Mann-Whitney rechaza la hipótesis de igualdad de distribución $(a=0,01)$. La duración del proceso ha sido de media un $21 \%$ más corta en los matrimonios mixtos. Si consideramos el conjunto de 225.418 casos donde ambos son solteros, desagregados en dos grupos (ambos españoles $N=213.763$, y mixtos $N=11.655$ ), tenemos que la duración media entre demanda y sentencia para ambos cónyuges españoles ha sido de 4,84 meses, y para mixtos, de 6,24 meses. La prueba T rechaza la hipótesis de igualdad de medias $(a=0,01)$, y la prueba no paramétrica $U$ de Mann-Whitney rechaza la hipótesis de igualdad de distribución $(a=0,01)$. La duración del proceso ha sido de media un $22 \%$ más corta en los matrimonios mixtos.

Por tanto, excluyendo las diferencias sociodemográficas de distancia de edad entre cónyuges y del estado civil prenupcial, sigue apreciándose un notable aumento en la duración del proceso de ruptura para los matrimonios mixtos. 


\subsubsection{La sentencia}

La resolución judicial conlleva el pronunciamiento y la regulación sobre a) pensión compensatoria para cónyuges, $b$ ) pensión alimenticia para hijos y c) custodia de hijos, una regulación que viene tensada por el mayor o menor nivel de entendimiento. $Y$ este mayor o menor nivel de entendimiento lo podemos medir a través del tipo de sentencia, que es el objeto de análisis del presente apartado.

Considerando las sentencias de "separación de mutuo acuerdo» más «divorcio consensuado sin separación previa» como sentencias de mayor nivel de entendimiento, y las sentencias de «separación contenciosa» más «divorcio no consensuado sin separación previa» como sentencias de menor nivel de entendimiento, se tiene que, para matrimonios en los que ambos son españoles, se alcanza un 69\% de sentencias de mayor nivel de entendimiento. Esta cifra baja a un $59 \%$ para las rupturas de matrimonios mixtos (gráfico 6) y se aprecia un menor peso relativo de separaciones frente a divorcios en el caso de matrimonios mixtos.

Para contrastar los datos expuestos anteriormente, se analizan tres tablas de contingencia. Un primer análisis, de doble entrada, para separaciones (mutuo acuerdo y contencioso) por tipo de matrimonio (ambos españoles y mixto), el coeficiente phi toma el valor 0 , se puede afirmar que no existe asociación. El segundo análisis, de doble entrada, para divorcios (consensuado y no consensuado) por tipo de matrimonio (ambos españoles y mixto), el coeficiente phi toma el valor 0 , se puede afirmar que no existe asociación. Por lo anterior,

Gráfico 6. Porcentajes por tipos de sentencias y combinaciones de nacionalidad de, al menos, un cónyuge español y, al menos, un hijo menor (2007-2011)

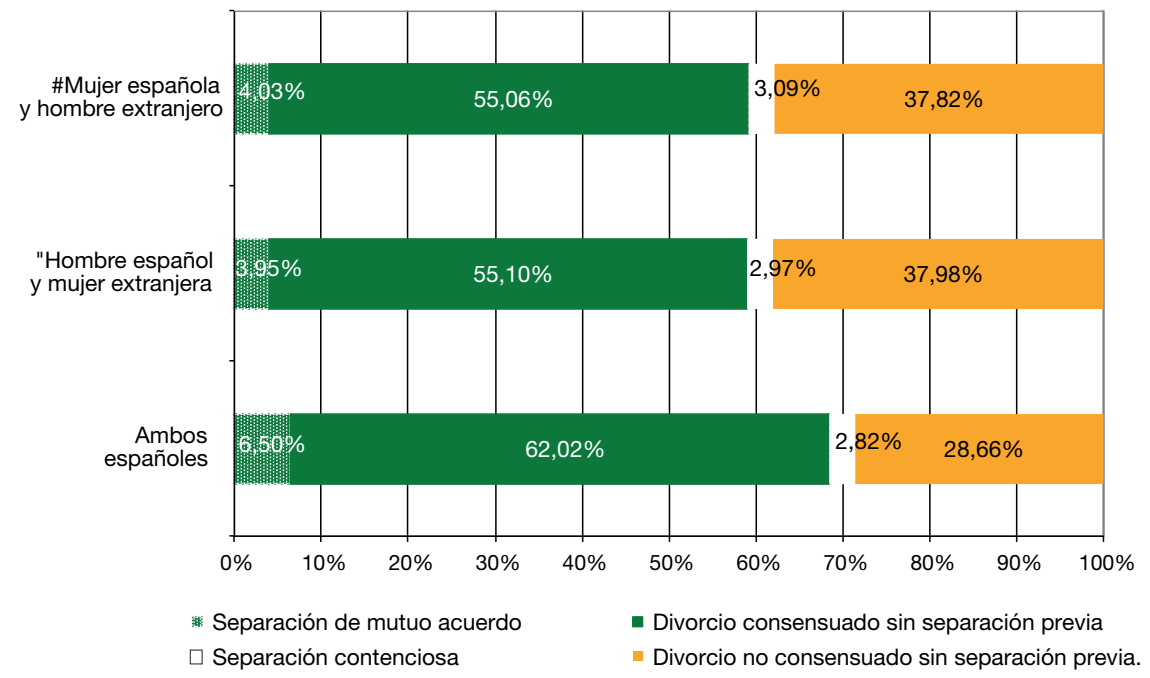

Fuente: porcentajes por columnas de la tabla 1 (apartado 3). 
se asume un resultado de sentencias distinto entre parejas en las que ambos cónyuges son españoles y en las que un cónyuge es español y otro no, donde los cónyuges españoles tienen un mayor nivel de entendimiento. En un tercer análisis, para tipo de matrimonio mixto (hombre español con mujer extranjera y mujer española con hombre extranjero) por tipo de sentencia (separaciones de mutuo acuerdo y contencioso, divorcio consensuado y no consensuado), se obtiene un coeficiente de contingencia con un valor 0,966 y se puede afirmar que existe una fuerte asociación, se asume un resultado de sentencias similar entre esposos y esposas españoles casados con extranjeros.

Para una tabla de contingencia entre tipo de sentencias y diferencia de edad (de 0 a 8 , y de 9 y más), el valor del coeficiente de contingencia es 0,037 y se descarta que exista relación. Y para una tabla de contingencia entre tipo de sentencias y estado civil prenupcial (divorciado con soltera y soltero con soltera), el valor del coeficiente de contingencia es 0,014 y se descarta que exista relación. Las diferencias sociodemográficas apreciables entre rupturas mixtas y rupturas en las que ambos miembros de la pareja son españoles no explican las diferencias en los tipos de sentencias, aunque existen más separaciones contenciosas y divorcios no consensuados en los matrimonios mixtos.

\subsubsection{La postruptura}

La regulación para el postdivorcio o la postseparación puede conllevar unas obligaciones para con el cónyuge (pensión compensatoria) y para con los hijos (pensión alimenticia), así como la determinación de la custodia de los menores. Son tres aspectos que conviene tratar por separado.

\subsubsection{Pensión compensatoria}

La pensión compensatoria nos ofrece indicios sobre la independencia económica o no de los cónyuges. En este sentido, está polarizada la mayor dependencia económica en las mujeres, y ello se da en todos los casos, como se puede advertir en la tabla 4. Sin embargo, se aprecia mayor poder económico en las esposas españolas casadas con extranjeros.

Para una tabla de contingencia de matrimonio mixto (tanto si está formado por un hombre español con una mujer extranjera, como por una mujer

Tabla 4. Porcentajes por columnas de la resolución de pensión compensatoria (2007-2011)

\begin{tabular}{lccc}
\hline & $\begin{array}{c}\text { Ambos } \\
\text { españoles }\end{array}$ & $\begin{array}{c}\text { Hombre español } \\
\text { y mujer extranjera }\end{array}$ & $\begin{array}{c}\text { Mujer española } \\
\text { y hombre extranjero }\end{array}$ \\
\hline $\begin{array}{l}\text { Esposa } \\
\text { (se asume dependencia del esposo) }\end{array}$ & $0,95 \%$ & $0,91 \%$ & $0,94 \%$ \\
$\begin{array}{l}\text { Esposo } \\
\text { (se asume dependencia de la esposa) }\end{array}$ & $12,10 \%$ & $12,14 \%$ & $8,50 \%$ \\
$\begin{array}{l}\text { No procede (se asume independencia } \\
\text { económica de ambos) }\end{array}$ & $86,95 \%$ & $86,95 \%$ & $90,56 \%$ \\
$N$ & 232.662 & 7.316 & 7.387 \\
\hline
\end{tabular}

Fuente: elaboración propia a partir de INE-NSD 2007-2011. 
Tabla 5. Porcentajes por columnas de la resolución de pensión alimentaria de menores (2007-2011)

\begin{tabular}{lccc}
\hline & $\begin{array}{c}\text { Ambos } \\
\text { españoles }\end{array}$ & $\begin{array}{c}\text { Hombre español } \\
\text { y mujer extranjera }\end{array}$ & $\begin{array}{c}\text { Mujer española } \\
\text { y hombre extranjero }\end{array}$ \\
\hline Esposo & $88,69 \%$ & $84,35 \%$ & $90,84 \%$ \\
Esposa & $4,50 \%$ & $8,70 \%$ & $4,16 \%$ \\
Ambos & $6,81 \%$ & $6,96 \%$ & $5,01 \%$ \\
$N$ & 232.582 & 7.312 & 7.380 \\
\hline
\end{tabular}

Fuente: elaboración propia a partir de INE-NSD 2007-2011.

española con un hombre extranjero) por pensión compensatoria, se obtiene un coeficiente de contingencia con valor 0,06 . Se puede afirmar que no existe asociación, se asumen diferencias entre esposos y esposas españoles casados con extranjeros en relación con la pensión compensatoria.

\subsubsection{Pensión alimenticia}

La pensión alimenticia nos puede aproximar — con cierta prudencia, pues no es una condición sine qua non- a la idea de quién de los esposos abandona el hogar conyugal, y en este sentido, por la polarización de los datos, podemos asumir que son los hombres en mayor medida, y en todos los casos sucede tanto en matrimonios en los que ambos son españoles como en matrimonios mixtos, como se puede advertir en la tabla 5. Sin embargo, se duplican en porcentaje relativo los casos de esposas extranjeras a quienes se les impone pensión alimentaria.

Para una tabla de contingencia de matrimonio mixto (formado por un hombre español y una mujer extranjera o una mujer española y un hombre extranjero) por pensión compensatoria, se obtiene un coeficiente de contingencia con valor 0,104 . Se puede afirmar que la asociación es muy débil, y se puede asumir diferencia entre esposos y esposas españoles casados con extranjeros en relación con la pensión alimenticia.

\subsubsection{Custodia de menores}

La custodia de menores es un factor muy correlacionado con la pensión alimenticia, pero ésta pone el foco sobre el poder económico, mientras que la custodia nos va a aproximar a la nueva realidad familiar de los cónyuges de matrimonios mixtos en el periodo postruptura. La tabla 6 pone de manifiesto la coherencia entre la pensión alimentaria y la custodia del esposo español de matrimonios mixtos, no así con la pensión alimentaria y la custodia de la esposa española de matrimonios mixtos, donde el peso relativo de custodias compartidas es menor y mantiene un peso relativo similar en las pensiones alimenticias a los matrimonios en los que ambos son españoles.

Para una tabla de contingencia de matrimonio mixto (formado por un hombre español y una mujer extranjera o una mujer española y un hombre extranjero) por custodia de menores, se obtiene un coeficiente de contingencia con valor 0,128 . Se puede afirmar que la asociación es muy débil, y se puede 
Tabla 6. Porcentajes por columnas de la resolución de custodia de menores (2007-2011)

\begin{tabular}{lccc}
\hline & $\begin{array}{c}\text { Ambos } \\
\text { españoles }\end{array}$ & $\begin{array}{c}\text { Hombre español } \\
\text { y mujer extranjera }\end{array}$ & $\begin{array}{c}\text { Mujer española } \\
\text { y hombre extranjero }\end{array}$ \\
\hline Esposo & $4,74 \%$ & $9,68 \%$ & $3,86 \%$ \\
Esposa & $84,17 \%$ & $78,87 \%$ & $87,45 \%$ \\
Compartida & $11,09 \%$ & $11,46 \%$ & $8,69 \%$ \\
$N$ & 231.651 & 7.285 & 7.371 \\
\hline
\end{tabular}

Fuente: elaboración propia a partir de INE-NSD 2007-2011.

asumir diferencia entre esposos y esposas españoles casados con extranjeros en relación con la custodia.

Para una tabla de contingencia entre custodia de menores y diferencia de edad (de 0 a 8 , y de 9 y más), el valor del coeficiente de contingencia es 0,033 y se descarta que exista relación. Para una tabla de contingencia entre custodia de menores y estado civil prenupcial (divorciado y soltera o soltero y soltera), el valor del coeficiente de contingencia es 0,006 y se descarta que exista relación. Las diferencias sociodemográficas apreciables entre rupturas mixtas y rupturas de parejas en las que ambos son españoles no explican las diferencias en la custodia de menores. Aquí la diferencia apreciable es que la custodia de menores se otorga más al cónyuge español, independientemente de su género.

\section{Conclusiones}

Tras el hecho de que España es un país receptor de inmigración (Malagón y Sarasola, 2005: 10) y que las interacciones sociales con la población autóctona han producido un aumento significativo en la formación de familias mixtas, si la nupcialidad en nuestro país ya no puede entenderse sin la aportación de los extranjeros, tampoco pueden entenderse las rupturas, ya que tienen un peso relativo del 10\% para 2011, en el total de disoluciones matrimoniales en las cuales está implicado un español o una española. Y no sólo es así, sino que se constata que los matrimonios mixtos con menores a cargo casi duplican el porcentaje de ruptura en los primeros cinco años de matrimonio en el periodo 2007-2011 frente a los matrimonios en los que ambos son españoles con menores a cargo en ese mismo periodo.

El «estreno», en 2007, de la variable nacionalidad en el boletín INE-NSD, ha coincidido con un lustro de gravísima depresión económica en España, que incluso ha perturbado la tendencia ascendente del divorcio entre 1981 a 2004, y muy ascendente tras la reforma de 2005, lo cual ha frenado en seco la larga serie histórica. Sin embargo, ha abierto una brecha en el comportamiento entre españoles, en función de si su cónyuge era extranjero o no. De hecho, en parejas mixtas, la mala situación de la economía general española no solo puede no ser un freno, sino también convertirse en un acicate. Esto sería especialmente cierto en el caso de que el cónyuge extranjero procediera de un 
país emergente que ofreciera oportunidades laborales mucho más abundantes y atractivas que las que, en estos momentos de crisis, España puede ofrecer y no existiera acuerdo en el cambio de residencia.

De un modo u otro, en los matrimonios mixtos, ha existido una menor tolerancia a periodos de reflexión o la libre voluntad de las partes, puesto que la coyuntura económica, de la que pocos hogares son ajenos, explica la recesión de demandas de separación o divorcio que conllevan un quebranto económico. Y resulta paradójico esta menor tolerancia en los matrimonios mixtos con menores, que, por ser así, tienen un estatus de doble nacionalidad, con dos referentes familiares, uno en cada país, que, en caso de ruptura, puede marcar una considerable distancia entre el hijo y uno de sus progenitores. Esto supondría un freno a los procesos o, al menos, una búsqueda de sentencia de divorcio consensuada o separación de mutuo acuerdo. Lo que ocurre, paradójicamente, es justamente lo contrario.

Podemos afirmar que el factor nacionalidad irrumpe con fuerza en las variables explicativas de los procesos de ruptura, y se constata, además, que las variables sociodemográficas características de las rupturas mixtas no explican por sí solas las diferencias entre ruptura matrimonial mixta y ruptura matrimonial en la que ambos miembros de la pareja son españoles, y debe ser controlada en las investigaciones de rupturas de parejas, pues de otro modo producirían sesgos en las conclusiones.

No sólo se constata que existen diferencias para una misma generación de españoles casados con españoles o casados con extranjeros y con menores a cargo, sobre la duración del matrimonio, la duración del proceso de ruptura, el tipo de sentencia y la custodia de hijos, sino que son sustancialmente más complejas, puesto que:

- Los matrimonios duran menos.

- Los procesos de ruptura duran más.

- Los tipos de sentencia son con un nivel de entendimiento menor.

- Hay menos custodia compartida.

Todo ello es un caldo de cultivo para que tengan lugar procesos postrupturales más complejos que los que experimentan los españoles separados o divorciados de otros españoles. Se constata, además, que los casos españoles de sustracción internacional de menores por parte de alguno de sus progenitores están creciendo con la misma intensidad que las rupturas mixtas de españoles y extranjeros con menores.

Y esto no es casual. Sin tener más instrumentos de medición, sabemos que los casos de solicitud de visita o de sustracción transfronteriza de niños por uno de sus progenitores con origen o destino España tienen un punto de partida, que es la ruptura de la pareja mixta con algún miembro español. Es necesario abrir líneas de investigación que puedan determinar qué grado de relación hay entre los periodos postruptura (que pueden derivar en una sustracción del menor) y la constatación de las condiciones adversas en el 
proceso de ruptura en matrimonios mixtos. Pero, además, es totalmente necesario disponer de registros de rupturas no matrimoniales. Queda constatado que, en el periodo 2007-2011, al menos ${ }^{9}$ el 28\% de las rupturas con hijos no era matrimonial.

No ha escapado a la observación que pudiera existir un recelo judicial sobre las parejas mixtas, porque una demanda conjunta, que a su vez deriva en una separación de mutuo acuerdo o en un divorcio consensuado, y en un marco posterior a la reforma de 2005, sigue un proceso judicial manifiestamente más largo, y esto hay que ponerlo en valor si se entiende que la excesiva duración del proceso puede condicionar negativamente aspectos de relevancia en la postruptura.

Por último, se manifiestan unas condiciones más favorables para los nacionales, puesto que, independientemente del género, el hombre español casado con extranjera tiene mayor tasa de custodia de menores que los hombres españoles casados con españolas, y la mujer española casada con extranjero tiene mayor tasa de custodia de menores que las mujeres españolas casadas con españoles. Esto explica que, en las demandas individuales interpuestas por las esposas y atendiendo al reclamo de establecer unas condiciones justas en la postruptura, es paradójico que, interpretando como perfil más vulnerable dentro del conjunto de esposas el de la esposa extranjera, sea ésta la que tiene el porcentaje más bajo de demandas individuales en comparación con el resto de esposas, y ocurre lo mismo para el caso de los esposos.

\section{Referencias bibliográficas}

Alaminos Chica, Antonio F. (2008). «Matrimonios mixtos intraeuropeos: Un modelo empírico». OBETS: Revista de Ciencias Sociales, 1, 131-149. $<$ http://dx.doi.org/10.14198/OBETS2008.1.07>

Alberdi, Inés (1981). «Sociología del divorcio». Revista Española de Investigaciones Sociológicas, 13, 183-193. $<\mathrm{http} / / /$ dx.doi.org/10.2307/40182839>

Cortina, Clara; García, Thaís y Esteve, Albert (2009). «Migración, ocupación y matrimonio: Una aproximación a las relaciones de género de las parejas mixtas en España». Estudios Demográficos y Urbanos, 24, 2 (71), 293-321.

García Pereiro, Thaís y Solsona i Pairó, Montserrat (2011). «El divorcio como nudo biográfico: Una revisión de la literatura reciente desde la perspectiva de la vulnerabilidad postdivorcio». Documents d'Anàlisi Geogràfica: Geografies de la infancia, la joventut i les famílies, 57 (1), 105-126.

Houle, René; Simó, Carles; Solsona, Montserrat y Treviño, Rocío (1999). «Análisis biográfico del divorcio en España». REIS: Revista Española de Investigaciones Sociológicas, 88, 11-35. <http://dx.doi.org/10.2307/40184202>

Jaime Castillo, Antonio M. (2000). «Reseña de Después del divorcio: Los efectos de la ruptura matrimoniali. Revista Española de Investigaciones Sociológicas, 91, 211-214. $<$ http://dx.doi.org/10.2307/40184286>

9. Se cuentan los casos judicializados que han llegado a un tribunal superior de justicia. 
Malagón, José Luis; Sarasola, José Luis (2005). Manual de atención social al inmigrante. Córdoba: Almuzara.

Roca, Jordi; Bodoque, Yolanda; Durdevic, Marija; Martínez, Lidia y Soronellas, Montserrat (2010). «Noviazgos transnacionales, migraciones por amor y formación de parejas mixtas en España». En: Soronellas Masdeu, Montserrat (coord.). Familias en la migración: Emociones, solidaridades y obligaciones en el espacio temporal. Barcelona: Icaria.

Rondón García, Luis Miguel (2012). Bases para la mediación familiar. Valencia: Tirant lo Blanch.

Ruiz Becerril, Diego (1999). Después del divorcio: Los efectos de la ruptura matrimonial en España. Madrid: Centro de Investigaciones Sociológicas (CIS) / Siglo XXI.

Santacreu, Oscar Antonio y Francés, Francisco José (2008). «Parejas mixtas de europeos en España: Integración, satisfacción y expectativas de futuro». OBETS: Revista de Ciencias Sociales, 1, 7-20. <http://dx.doi.org/10.14198/OBETS2008.1.01>

Sbarra, David A.; Law, Rita W.; Portley, Robert M. (2011). «Divorce and death: A meta-analysis and research agenda for clinical, social, and health psychology». Perspectives on Psychological Science, 5 (6), 454-474. $<$ http://dx.doi.org/10.1177/1745691611414724>

Simó, Carles y Solsona, Montserrat (2010). «El registro estadístico de las rupturas de unión en España: Evaluación e ideas para avanzar desde la demografía». Papers: Revista de Sociologia, 95 (3), 609-632.

Solsona i Pairó, Montserrat (2011). «Biografías de divorcio: Cambios de estado borrosos y trayectorias familiares complejas». Revista Notas de Población, 93, 77-105.

Solsona, Montserrat y Simó, Carles (2007). «Evolución histórica del divorcio en España desde la aprobación de la ley de 1981 hasta la reforma de 2004». En: CABré, Anna (coord.). La constitución familiar en España. Bilbao: Fundación BBVA.

Steingress, Gerhard (2012). «Parejas mixtas e hibridación transcultural en España: Reflexiones sobre un nuevo fenómeno desde perspectivas comparativas a nivel europeo». Papers: Revista de Sociología, 97 (1), 11-37.

Vallejo Orellana, Reyes; Sánchez-Barranco, Fernando y Sánchez-Barranco, Pablo (2004). «Separación o divorcio: Trastornos psicológicos en los padres y los hijos». Revista de la Asociación Española de Neuropsiquiatría, 92, 91-110. <http://dx.doi.org/10.4321/s0211-57352004000400006>

Vidal Fernández, Begoña (2010). «Protección jurisdiccional de los hijos en los casos de ruptura de los matrimonios mixtos: Especial consideración de la regulación adoptada en el espacio europeo de libertad, seguridad y justicia». Revista de Estudios Europeos, 55, 105-134. 